acceptance of the children's difficulties as constitutional: neither wilful nor parent engendered. In later life, many of them had good work achievements and many married, but their overall work adjustment, their heterosexual adjustment, and their psychiatric state were worse than those of other referred children grown up (S Wolff, to be published).

These children resembled the schizotypal children described by Nagy and Szatmari, ${ }^{10}$ and their difficulties certainly overlapped with those of the patients of Wing and Tantam. But whether they too should be included in an 'autistic spectrum' will depend on the results of more definitive genetic studies.

For this reason, the arguments put forward by Professor Cox in this issue against a global diagnosis of autism, ${ }^{11} 12$ and in defence of a distinct diagnostic category of Asperger's syndrome, although based on Wing's rather narrow definition, are to be welcomed.

Dorothy Bishop, like other workers, considers Asperger's syndrome to overlap both with autism and with specific developmental language disorders, often diagnosed as congenital dysphasia. ${ }^{13} \mathrm{~A}$ number of children with these disabilities also have the social impairments of Asperger/schizoid disorders. She suggests a two dimensional model for autistic type disorders, with impaired meaningful verbal communication on one axis and impaired social relationships with circumscribed interest patterns on the other. Asperger's syndrome, on this model, would overlap both with autism and with specific language disorders, but would be characterised by low scores on the language disorder dimension and high scores on the social impairment/circumscribed interests dimension.

Work on the diagnosis of these disorders is of theoretical interest, especially in disentangling the causal factors involved. It is also of great clinical importance. Children with severe forms of Asperger's syndrome will need the same services as well functioning autistic children. The more intelligent and less obviously handicapped Asperger/ schizoid children require above all to be identified as constitutionally impaired. ${ }^{14}$ Their special make up needs to be understood. They may also need special arrangements made, particularly at school, in the knowledge that in later life when pressures for conformity are less than during the school years, many will be able to find their social niche, and a few to develop their rather exceptional gifts.

SULA WOLFF

University Department of Psychiatry,

The Kennedy Tower,

Royal Edinburgh Hospital,

Morningside Park,

Edinburgh E10 SHF

1 Asperger H. Die autistischen Psychopathen im Kindesalter. Archiv fuer Psychiatrie und Nervenkrankheiten 1944;177:76-137.

2 Weber D. Autistische syndrome. In: Remschmidt H, Schmidt MH, eds. Kinder- und fugendpsychiatrie in Klinik und Praxis. Vol II. Stuttgart: Georg Thieme, 1985:269-98.

3 Asperger H. Problems of infantile autism. Communication 1979;13:45-52. 4 Wing L. Asperger's syndrome: a clinical account. Psychol Med 1981;11:115-

5 Tantam D. Lifelong eccentricity and social isolation. I: psychiatric, social and forensic aspects. Br $\mathcal{f}$ Psychiatry 1988;153:777-82.

6 Gillberg C. Autism and pervasive developmental disorders. Annual research review. I Child Psychol Psychiatry 1990;31:99-120.

7 Wing L. Autism: possible clues to the underlying pathology-clinical facts. In: Wing L, ed. Aspects of autism: biological research. London: The Nationa Autistic Society/Gaskell/Royal College of Psychiatrists, 1988:1-10.

- 8 Gillberg C. Asperger syndrome in 23 Swedish children. Dev Med Child Neurol 1989;31:520-31.

9 Wolff S, Chick J. Schizoid personality in childhood: a controlled follow-up study. Psychol Med 1980;10:85-100.

10 Nagy J, Szatmari P. A chart review of schizotypal personality disorders in children. F Autism Dev Disord 1986;16:351-67.

11 Cox AD. Is Asperger's syndrome a useful diagnosis? Arch Dis Child 1991;66:259-62.

12 Shopler E. Convergence of learning disability, higher-level autism, and Asperger's syndrome. F Autism Dev Disord 1985;15:359.

13 Bishop DVM Autism, Asperger's syndrome and semantic-pragmatic dis order: whe Autsm, Asperger's syndrome and semantic-pragmatic dis-

14 Perkins M, Wolkind SN. Asperger's syndrome: who is being abused? Arch Dis Child 1991 (in press).

\title{
Possible aetiological factors in childhood leukaemia
}

Leukaemia accounts for over half of all cancers diagnosed in children, with one in 2000 developing the disease before their 15th birthday. ${ }^{1-3}$ Despite considerable improvements in treatment over the last 20 years, about half of those who develop childhood leukaemia die within five years of diagnosis. Speculations about the causes of leukaemia in children abound, and several new and exciting theories have recently been suggested.

\section{Ionising radiation}

Exposure to ionising radiation is known to cause leukaemia. ${ }^{45}$ Furthermore, the fetus and young child seem to be more susceptible to the effects of ionising radiation than the adult. ${ }^{6-9}$ The controversial suggestion of Stewart $e t$ $a l$, made in 1958, that prenatal exposure to $x$ rays might increase the risk of childhood leukaemia has taken several decades to settle. It is now widely accepted that as much as $5 \%$ of all childhood leukaemias could be caused by diagnostic radiography of the mother's abdomen while the child is in utero. ${ }^{7-10}$

Today, the possible contribution of natural radiation is a controversial topic. Estimates of the proportion of all childhood leukaemias attributable to background radiation range from a few percent to nearly all. ${ }^{71-13}$ Assumptions about the relative effects of external gamma radiation and internal alpha particles on children of different ages and babies of different gestations alter these estimates appreciably. ${ }^{711}$ Discussion has intensified recently after the report by $\mathrm{Dr}$ Henshaw and his colleagues demonstrating a correlation between indoor radon levels in different countries and the incidence of leukaemia and other cancers in children. ${ }^{12}$ They suggest that a sizable proportion of all childhood leukaemias could be caused by exposure to radon gas in the home. These issues are now being vigorously investigated, but at this stage the aetiological relevance of natural background radiation is unclear.

More controversial still is the hypothesis that germ cell mutations induced by ionising radiation might increase the risk of leukaemia in the progeny of those exposed. This suggestion comes from the investigations of Professor Gardner and his colleagues of the raised incidence of childhood leukaemia near the Sellafield reprocessing plant in West Cumbria. ${ }^{14}$ They found that exposure of fathers at work to comparatively low doses of external ionising radiation was associated with an increased risk of leukaemia in their offspring. The main finding of a sixfold to eightfold excess in the children of those most heavily exposed is, however, based on only four cases. As well as exposure of fathers at work to ionising radiation, other explanations are possible. ${ }^{14-18}$ For example, external gamma radiation may not be the relevant exposure and exposure at work to other harmful agents may be involved. In particular, it has been hypothesised that radionuclides may accumulate in the male reproductive organs. Such a mechanism could explain both the high mortality from prostatic cancer found in highly exposed nuclear workers, and the increased incidence of leukaemia in the offspring of radiation workers at Sellafield. ${ }^{16} 17$ Mothers' exposure to radiation before and during pregnancy may also be important, and could occur if 
contaminated clothing or equipment were brought home from the place of work. ${ }^{14-18}$ Two studies, similar to that of Gardner et al, of leukaemia and non-Hodgkin's lymphoma in the vicinity of nuclear establishments are in progress in the United Kingdom. One is taking place around the United Kingdom Atomic Authority plant of Dounreay and the other around Atomic Weapons Establishments at Aldermaston and Burghfield. These should help to clarify the relation between childhood leukaemia and parental employment in the nuclear industry.

\section{Infectious disease}

There has been considerable speculation about the possible aetiological role of infectious diseases. ${ }^{45}$ Initially, after the identification of leukaemogenic viruses in animals, similar human viruses were sought. Despite intensive investigations, no specific human virus has been identified and interest has shifted to the possible effects of common viruses. The suggestion is that childhood leukaemia results as a rare response to a common, possibly sublinical, infection. ${ }^{19-21}$ More specifically, Greaves has hypothesised that the immune response itself promotes the development of leukaemia by inducing proliferative stress in bone marrow lymphocyte precursors, thus increasing the risk of spontaneous mutations. ${ }^{19} 20$ Indirect support for the involvement of infectious agents comes from the characteristically sharp peak in incidence of the common childhood form of acute lymphoblastic leukaemia that occurs at around 3 years of age. This is the age when many children first begin to attend playgroup and school, and for some children this would result in their first significant exposure to infection. Reports that childhood leukaemia may be more common in higher social classes and in first or only children suggests that susceptibility may be similar to the polio model. ${ }^{4519}{ }^{20}$ Kinlen has further hypothesised that isolation and migration might be important, and has suggested that children living in isolated rural communities who come into contact with individuals from more urban areas might be at increased risk. ${ }^{21}$ Despite its appeal there is still no direct evidence to support the infectious disease hypothesis in humans, but this topic continues to be the subject of intensive research.

\section{Drugs}

Apart from ionising radiation, chemotherapy is the only other established cause of leukaemia. Its contribution to the total amount of childhood disease is, however, small as it has been shown to increase the risk of acute myeloid leukaemia only, which is rare in children. ${ }^{45}$ Other drugs recently mooted to cause childhood leukaemia include the antibiotic chloramphenicol ${ }^{22}$ and more recently in utero exposure to marijuana. ${ }^{23}$

\section{Other chemical and physical exposures}

Exposure of parents both at work and at home to a number of potentially toxic chemicals have been suggested as risk factors for childhood leukaemia. Most epidemiological investigations of parental exposure have, however, been based on small numbers and on information collected routinely at death or cancer registration. To date, the evidence supporting an association between childhood leukaemia and compounds such as benzene and lead is weak and contradictory. 2224

Non-ionising electromagnetic radiation has also been suspected as increasing the risk of leukaemia and other cancers. Particular concern has been expressed about residence near power lines and use of electric blankets. ${ }^{25} 26$ Again, the epidemiological evidence is inconsistent and the data are diffi- cult to interpret, mainly because of the lack of reliable measures of exposure.

\section{Chromosomal anomalies}

About 3\% of all childhood leukaemias are associated with recognisable chromosomal disorders, such as Down's syndrome, Klinefelter's syndrome, and Fanconi's anaemia. ${ }^{45}$ In these congenital or hereditary syndromes, the chromosomal abnormality appears to place the individual at increased risk of disease. For the majority of leukaemias, however, the significance of the chromosomal abnormalities found in all leukaemic cells is unclear.

\section{Conclusion}

Leukaemia is the major paediatric malignancy of developed countries. Recent advances in the treatment of childhood leukaemia have not been matched by similar advances in the understanding of its aetiology. At present, ionising radiation and chemotherapy are the only established causes of leukaemia, although many other plausible hypotheses remain.

EVE ROMAN VALERIE BERAL

Imperial Cancer Research Fund,

Cancer Epidemiology Unit,

Gibson Building,

Radcliffe Infirmary,

Oxford OX2 $6 H E$

1 Parkin DM, Stiller CA, Draper GJ, Biet-r CA, Terracini B, Young JL, eds. International incidence of childhood cancer. Lyon: International Agency for Research on Cancer, 1988. (IARC Scientific Publications No 87.)

2 Office of Population Censuses and Surveys. Mortality statistics childhood: review of the registrar general on deaths in England and Wales, 1985. HMSO London, 1987. (Series DH3 No 19.)

Office of Populations Censuses and Surveys. Childhood cancer in Britain incidence, survival and mortality. In: Draper GJ, Birch JM, Bithell JF, $e$ $a l$, eds. Studies on medical and population subjects No 37. London: HMSO, 1982 .

4 Linet MS. The leukaemias: epidemiologic aspects. Monographs in epidemiology and biostatistics. Vol 6. Oxford: Oxford University Press, 1985.

5 Doll R. The epidemiology of childhood leukaemia. Foumal of the Royal Statistical Society A 1989;152:341-51.

6 Stewart AM, Webb JW, Giles BD. A survey of childhood malignancies. BMF 1958;i:1495-508.

7 Gilman EA, Kneale GW, Knox EG, Stewart AM. Pregnancy X-rays and childhood cancers: effects of exposure age and radiation dose. Foumal of Radiological Protection 1988;8:3-8.

8 Bithell JF, Stiller CA. A new calculation of the carcinogenic risk of obstetric X-raying. Stats Med 1988;7:857-64.

MacMahon B. Some recent issues in low-exposure radiation epidemiology. Environ Health Perspect 1989;81:131-5.

10 Mole RH. Childhood cancer after prenatal exposure to diagnostic X-ray examination in Britain. Br $\mathcal{f}$ Cancer 1990;62:152-68.

11 Knox EG, Stewart AM, Gilman EA, Kneale GW. Background radiation and childhood cancer. Fournal of Radiological Protection 1988;8:9-18.

12 Henshaw DL, Eatough JP, Richardson RB. Radon as a causative factor in induction of myeloid leukaemia and other cancers. Lancet 1990;335: 1008-12.

13 Butland BK, Muirhead CR, Draper GJ. Radon and leukaemia. Lance 1990;335:1338-9.

14 Gardner MJ, Snee MP, Hall AJ, Powell CA, Downes S, Terrell JD. Results of case-control study of leukaemia and lymphoma among young people near the Sellafield nuclear plant in West Cumbria. BMY 1990;300:423-9.

15 Peto J. Radon and the risks of cancer. Nature 1990;345:389-90.

16 Beral V. Leukaemia and nuclear installations. $B M \mathcal{F} 1990 ; 300: 411-2$.

17 Eatough JP, Henshaw DL. Radon and prostate cancer. Lancet 1990;335:1292.

18 Evans HI. Leukaemia and radiation. Nature 1990;345:16-7.

19 Greaves MF. Speculations on the cause of childhood acute lymphoblastic leukaemia. Leukaemia 1988;2:120-5.

20 Greaves MF. Infective cause of childhood leukaemia. Lancet 1989;i:95.

21 Kinlen L. Evidence for an infective cause of childhood leukaemia: comparison of a Scottish new town with nuclear reprocessing sites in Britain. Lancet of a Scottish new

22 Shu XO, Gao YT, Brinton LA, et al. A population-based case-control study of childhood leukaemia in Shanghai. Cancer 1988;62:635-44.

23 Robison LL, Buckley JD, Daigle AE, et al. Maternal drug use and risk of childhood non-lymphoblastic leukaemia among offspring. Cancer 1989;63: childhood

24 Arundel SE, Kinnier-Wilson LM. Parental occupations and cancer: a review of the literature. I Epidemiol Community Health 1986;40:30-6.

25 Coleman M, Beral V. A review of epidemiological studies of the health of liv ing near or working with electricity generation and transmission equipment. Int $\mathcal{J}$ Epidemiol 1988;17:1-13.

26 Savitz DA, John EM, Klecknar RC. Magnetic field exposure from electric appliances and childhood cancer. Am $\mathcal{J}$ Epidemiol 1990;131:763-73. 